\title{
Piezoelectric and Dielectric Properties of $\left(\mathrm{Bi}_{0.5} \mathrm{Na}_{0.5}\right) \mathrm{TiO}_{3}-\mathrm{Ba}\left(\mathrm{Zr}_{0.04} \mathrm{Ti}_{0.96}\right) \mathrm{O}_{3}$ Lead-Free Piezoelectric Ceramics
}

\author{
Zhiwu CHEN, Anze SHUI, Zhenya LU and Pingan LIU \\ College of Materials Science and Engineering, South China University of Technology, Guangzhou, Guangdong 510641 PR China
}

\author{
鉛無し圧電セラミックス $\left(\mathrm{Bi}_{0.5} \mathrm{Na}_{0.5}\right) \mathrm{TiO}_{3}-\mathrm{Ba}\left(\mathrm{Zr}_{0.04} \mathrm{Ti}_{0.96}\right) \mathrm{O}_{3}$ の圧電と誘電特性 \\ 陳 志武·税 安澤·卢 振覀·劉 平安 \\ 華南理工大学材料学院, 510640 中国広東省広州市
}

\begin{abstract}
Lead-free piezoelectric ceramics $(1-x)\left(\mathrm{Bi}_{0.5} \mathbf{N a}_{0.5}\right) \mathrm{TiO}_{3-x} \mathbf{B a}\left(\mathrm{Zr}_{0.04} \mathrm{Ti}_{0.96}\right) \mathbf{O}_{3}$ (abbreviated as BNT-BZT100x, with $x$ ranged from 2 to $10 \mathrm{~mol} \%$ ) have been investigated. The samples were prepared by a conventional sintering technique. Effect of amount of BZT on the electrical properties and microstructures of BNT-BZT lead-free piezoelectric ceramic were examined. The $X$-ray diffraction (XRD) patterns shows that incorporated BZT diffuses into the BNT lattice to form a solid solution during sintering, but changes the crystal structure from rhombohedral to tetragonal symmetry at higher BZT amounts. The measurements of piezoelectric properties reveal that BNT-BZT6 ceramics has highest piezoelectric performance: the piezoelectric constant $d_{33}$ reached to $168 \mathrm{pC} / \mathrm{N}$ and planar electromechanical coupling factor $k_{\mathrm{p}}$ enhanced to 0.27 . The morphotropic phase boundary (MPB) between BNT (rhombohedral) and $\mathrm{Ba}\left(\mathrm{Zr}_{0.04} \mathrm{Ti}_{0.96}\right) \mathrm{O}_{3}$ (tetragonal) should be near the BNT-BZT6 composition.

[Received August 10, 2006; Accepted September 21, 2006]
\end{abstract}

Key-words : Lead-free piezoelectric ceramics, Morphotropic phase boundary, Piezoelectric property

\section{Introduction}

In recent years, lead-free piezoelectric ceramics have attracted considerable attentions as one of important piezoelectric materials because of its outstanding advantages in free control atmosphere and no lead pollution. $\left(\mathrm{Bi}_{0.5} \mathrm{Na}_{0.5}\right) \mathrm{TiO}_{3}$ composition (abbreviated as BNT) is an important lead-free piezoelectric material with a rhombohedral perovskite structure discovered by Smolenskii et al. in 1960. ${ }^{1}$ As $\left(\mathrm{Bi}_{0.5} \mathrm{Na}_{0.5}\right) \mathrm{TiO}_{3}$ composition exhibits a strong ferroelectricity and high Curie temperature $T_{\mathrm{c}}=320^{\circ} \mathrm{C},{ }^{2)-4)}$ it has been considered to be a good candidate of lead-free piezoelectric ceramics to replace the widely used lead-based piezoelectric materials. However, this material has a drawback of high conductivity to cause problems in poling process. To improve its properties, some modifications on BNT composition have been performed. It has been reported that BNT-based compositions modified with $\mathrm{BaTiO}_{3},{ }^{5)} \mathrm{NaNbO}_{3},{ }^{6)} \mathrm{BiFeO}_{3},{ }^{7)}\left(\mathrm{Bi}_{0.5} \mathrm{~K}_{0.5}\right) \mathrm{TiO}_{3}{ }^{8)}$ or $\mathrm{La}_{2} \mathrm{O}_{3}{ }^{9)}$ showed improved piezoelectric properties and easier treatment in polling process comparing with pure BNT ceramics. Among them, $\mathrm{BaTiO}_{3}$ (BT) is well-known lead-free piezoelectric materials with a tetragonal phase. It was reported that MPB compositions exist in the case of $x=0.06-0.07$ for $(1-x)\left(\mathrm{Bi}_{0.5} \mathrm{Na}_{0.5}\right) \mathrm{TiO}_{3-x} \mathrm{BaTiO}_{3}$.

$\mathrm{Ba}\left(\mathrm{Zr}_{0.04} \mathrm{Ti}_{0.96}\right) \mathrm{O}_{3}$, as well as $\mathrm{BaTiO}_{3}$, has an tetragonal symmetry at room temperature. $\mathrm{Ba}\left(\mathrm{Zr}_{0.04} \mathrm{Ti}_{0.96}\right) \mathrm{O}_{3}$ (BZT) ceramic are known to have high piezoelectric and dielectric properties. ${ }^{10), 11)}$ The solid solution of BNT and BZT seem to have MPB between the tetragonal and rhombohedral phases. It is well known that large piezoelectric properties can be expected at the MPB composition. ${ }^{12)}$ However, there have been few studies on the properties of BNT ceramics modified with $\mathrm{Ba}\left(\mathrm{Zr}_{0.04} \mathrm{Ti}_{0.96}\right) \mathrm{O}_{3}$.

In the present work, $\mathrm{Ba}\left(\mathrm{Zr}_{0.04} \mathrm{Ti}_{0.96}\right) \mathrm{O}_{3}$ was added into BNT ceramics as an additive based on the formula $(1-x)$

Funakubo, H. (Contributing Editor)
$\left(\mathrm{Bi}_{0.5} \mathrm{Na}_{0.5}\right) \mathrm{TiO}_{3-x} \mathrm{Ba}\left(\mathrm{Zr}_{0.04} \mathrm{Ti}_{0.96}\right) \mathrm{O}_{3}$ (abbreviated as BNTBZT100x, with $x$ ranged from 2 to $10 \mathrm{~mol} \%$ ), and its effects on the microstructure as well as on the dielectric and piezoelectric properties of the ceramics were investigated. We attempt to determine the existence of MPB and the enhancement of the properties for $\left(\mathrm{Bi}_{0.5} \mathrm{Na}_{0.5}\right) \mathrm{TiO}_{3}$ and $\mathrm{Ba}\left(\mathrm{Zr}_{0.04}\right.$ $\left.\mathrm{Ti}_{0.96}\right) \mathrm{O}_{3}$ systems with rhombohedral and tetragonal crystal structures, respectively.

\section{Experimental procedure}

BNT-BZT100x ceramics were prepared by a conventional mixed-oxide technique using commercially available metal oxides or carbonate powders: $\mathrm{Bi}_{2} \mathrm{O}_{3}, \mathrm{Na}_{2} \mathrm{CO}_{3}, \mathrm{BaCO}_{3}, \mathrm{ZrO}_{2}$ and $\mathrm{TiO}_{2}$. The powders were weighed and mixed well in alcohol with zirconium balls by ball-milling for $10 \mathrm{~h}$. The calcination was then conducted at $800^{\circ} \mathrm{C}$ for $2 \mathrm{~h}$. The calcined mixture was ball-milled in alcohol again for $6 \mathrm{~h}$. After drying, it was mixed thoroughly with a PVA binder solution and uniaxially pressed into disk samples with a diameter of $20 \mathrm{~mm}$ and a thickness of $2 \mathrm{~mm}$. The disk sample was then sintered at $1150^{\circ} \mathrm{C}$ for $2 \mathrm{~h}$ in air. The crystallite structure of the sintered sample was examined using an X-ray diffractometer (XRD, $\mathrm{D} / \mathrm{Max}-3 \mathrm{C}$, Japan) with $\mathrm{Cu} \mathrm{K} \alpha$ radiation.

Silver paste was applied to the top and bottom surfaces of the samples as electrodes. The ceramic samples were polarized under a dc field of $7.5 \mathrm{kV} / \mathrm{mm}$ at $100^{\circ} \mathrm{C}$ in a silicon oil bath for 15 min. Piezoelectric constant $d_{33}$ of the samples were measured by means of quasistatic $d_{33}$ meter $(\mathrm{ZJ}-3 \mathrm{~A})$ based on Berlincourt method. Dielectric constant $\varepsilon_{33}{ }^{T} / \varepsilon_{0}$ was obtained by measuring the capacitance at $1 \mathrm{kHz}$ using an impedance analyzer (HP4192A). Resonance measurements were performed using an impedance analyzer (HP 4294A). The electromechanical coupling factors $k_{\mathrm{p}}$ were calculated from the resonance and the anti-resonance frequencies according to Onoe's formulas. ${ }^{13}$ 


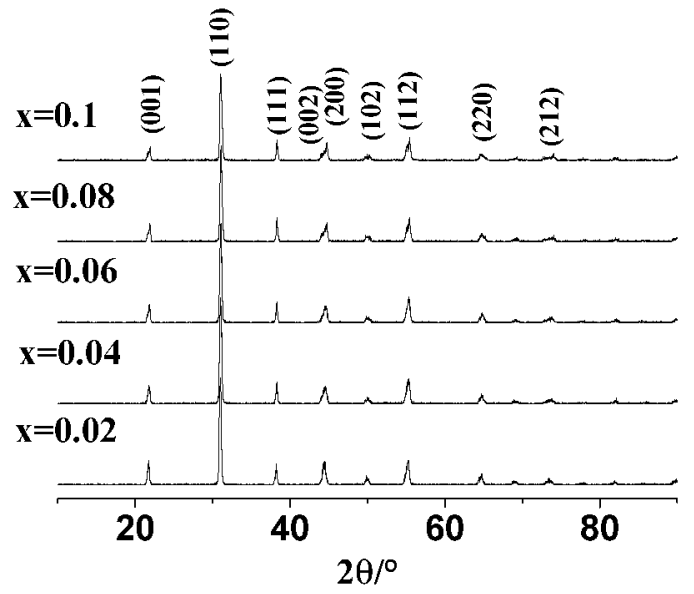

Fig. 1. X-ray diffraction patterns of BNT-BZT100x system (with $x$ ranged from 2 to $1 \mathrm{~mol} \%$ ).

\section{Results and discussion}

The BNT-BZT100 $x$ ceramics were well sintered at $1150^{\circ} \mathrm{C}$ with a high-density ratio of more than $95 \%$ of the theoretical density for $2 \mathrm{~h}$ in air. As show in Fig. 1, all of the X-ray diffraction (XRD) patterns of the BNT-BZT100x ceramics have pure perovskite structure. BZT appears to have diffused into the lattice to form a solid solution. In this case, barium can occupy a $(\mathrm{Bi}, \mathrm{Na})$ site and $\left(\mathrm{Zr}_{0.04} \mathrm{Ti}_{0.96}\right)$ can enter a titanium site of BNT.

The XRD patterns of the samples in the $2 \theta$ ranges of $45-$ $51^{\circ}$ are shown in Fig. 2. It is evident that at room temperature, BNT is in rhombohedral phase and $\mathrm{Ba}\left(\mathrm{Zr}_{0.04} \mathrm{Ti}_{0.96}\right) \mathrm{O}_{3}$ is in tetragonal phase. Only the (200) peak is observed in the diffraction patterns for BNT-BZT100x $(x=0.02,0.04)$ which have a rhombohedral structure. On the other hand, (200) and (002) peaks are observed in the diffraction patterns for BNT-BZT100 $x(x=0.1)$ which have a tetragonal structure. At $6 \mathrm{~mol} \% \mathrm{BZT}$, no obvious change in the XRD pattern was observed compared with that of BNT-BZT4 ceramics, but the peak at around $47.5^{\circ}$ is slightly asymmetrical, featured with slightly splitting of the (200) and (002) peaks. More BZT leads to the (200) and (002) peaks separated more widely, indicating the increasing tetragonality of the lattice. Hence, it can be inferred that there should exist a rhombohedraltetragonal morphotropic phase boundary in the BNTBZT100x $(x=0.02-0.1)$ composition. Figure 3 shows the lattice parameters of samples of the BNT-BZT100x system. In the region of the tetragonal phase, the lattice parameter $a$ and $c$ increases gradually with an increasing amount of the BZT phase $(x)$. The difference between $a$ and $c$ also increases with increasing $x$.

The interplanar distance $d_{(h, k, l)}$ of tetragonal phase is expressed as

$$
d_{(h, k, l)}=\frac{a}{\sqrt{h^{2}+k^{2}+\left(\frac{a}{c}\right)^{2} l^{2}}}
$$

where $a, c$ are the lattice parameter, $h, k, l$ are indices of crystallographic plane. The Bragg equation is expressed as follows:

$$
2_{(h, k, l)} \operatorname{Sin} \theta=\lambda
$$

where $\theta$ is Bragg angle, $\lambda$ is wavelength. Combining the Eqs. (1) and (2), Sin $\theta$ can be expressed as

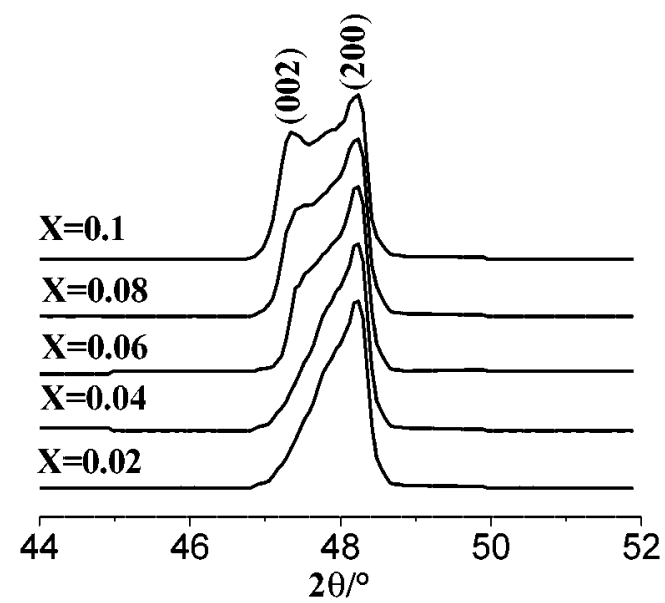

Fig. 2. X-ray diffraction patterns of BNT-BZT100 $x$ system in the $2 \theta$ range of $44-52^{\circ}$.

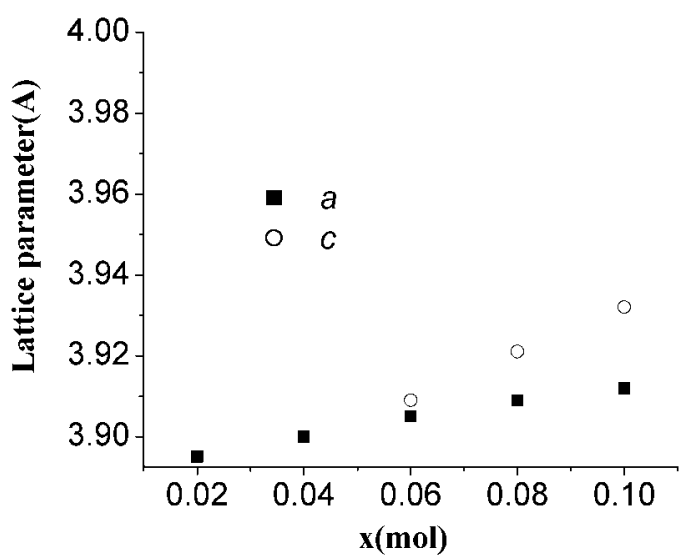

Fig. 3. Lattice parameter as a function of composition for BNTBZT100x system.

$$
\operatorname{Sin} \theta=\frac{\lambda}{2} \sqrt{\frac{h^{2}+k^{2}}{a^{2}}+\frac{l^{2}}{c^{2}}}
$$

From Eq. (3), we have

$$
\theta_{(200)}-\theta_{(002)}=\operatorname{arcSin}\left(\frac{\lambda}{a}\right)-\operatorname{arcSin}\left(\frac{\lambda}{c}\right)
$$

where $\theta_{(200)}$ and $\theta_{(002)}$ are Bragg angle for (200) and (002) crystal plane respectively. As the difference between $a$ and $c$ also increases with increasing $x$, from Eq. (4), it is easy to explain why more BZT leads to the (200) and (002) peaks separated more widely.

Figure 4 shows the dependence of the planar electromechanical coupling factor $k_{\mathrm{p}}$ and piezoelectric constant $d_{33}$ on the chemical composition for the synthesized BNTBZT100x ceramics. Coupling factor $K_{\mathrm{p}}$ increases with the amount of BZT up to $6 \mathrm{~mol} \%$ and then decreases with further increase in BZT amount. At $6 \mathrm{~mol} \% \mathrm{BZT}$, the sample shows the optimal $k_{\mathrm{p}}$ of $27 \%$. Variation of the piezoelectric constant $d_{33}$ with BZT amount is almost similar to that of $k_{\mathrm{p}}$. The optimized BZT amount is also about $6 \mathrm{~mol} \%$, giving maximum $d_{33}$ value of $168 \mathrm{pC} / \mathrm{N}$. Figure 5 shows the dependence of the dielectric constant $\varepsilon_{33}{ }^{T} / \varepsilon_{0}$ and dissipation factor $\tan \delta$ on the chemical composition for BNT-BZT100x. Dielectric constant $\varepsilon_{33}{ }^{T} / \varepsilon_{0}$ of the samples increases with increasing BZT 


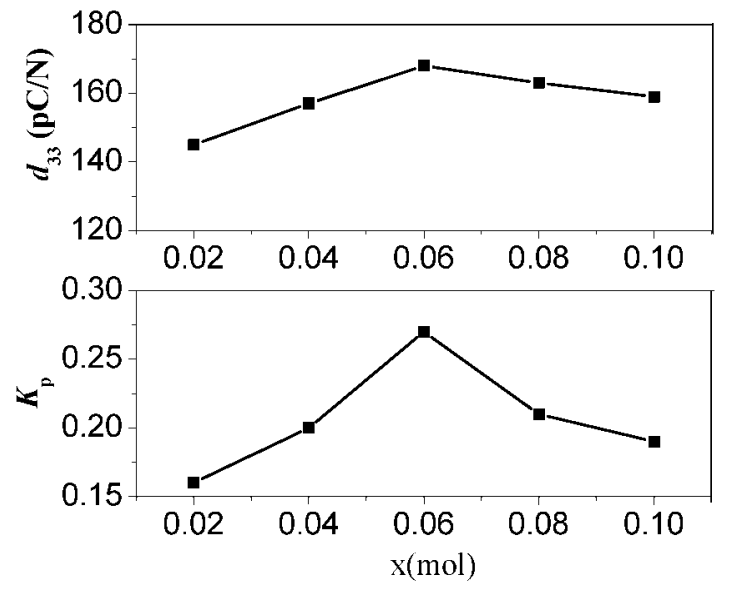

Fig. 4. Piezoelectric constant $d_{33}$ and planar electromechanical coupling factor $k_{\mathrm{p}}$ as a function of composition for BNT-BZT100x system.

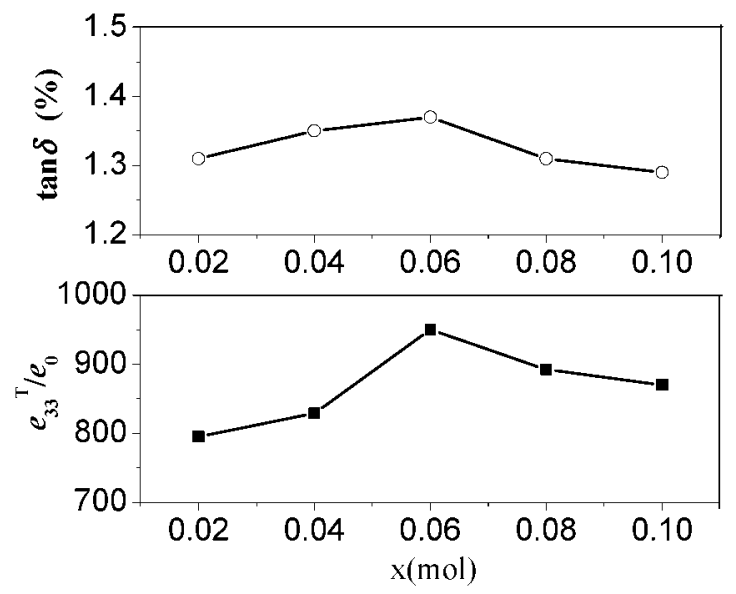

Fig. 5. Dielectric constant $\varepsilon_{33}{ }^{T} / \varepsilon_{0}$ and dissipation factor $\tan \delta$ as a function of composition for BNT-BZT100x system.

amount initially, reaches the maximum at $6 \mathrm{~mol} \%\left(\varepsilon_{33}{ }^{T} / \varepsilon_{0}=\right.$ 950) of BZT and then decreases with more BZT. Variation of the dissipation factor $\tan \delta$ with BZT amount is similar to that of $\varepsilon_{33}{ }^{T} / \varepsilon_{0}$, and at $x=0.06$, the samples have relatively high $\tan \delta(\tan \delta=1.37 \%)$. In summary, it can be seen that the optimal electromechanical property occurs in BNT-BZT6 composition. Combining the result of XRD, it can be concluded that the morphotropic phase boundary (MPB) should be near the BNT-BZT6 composition.

The effect of BZT addition on the properties of BNT ceramics can be attributed to two factors: the chemical modification of the material and the influence on microstructure. At a small amount of BZT, chemical modification caused by dissolution of BZT into the BNT lattice plays a major role on the properties of BNT-BZT ceramics. When the added amounts of BZT are increased to cause change in microstructure, the influence of microstructure on the properties of BNT-BZT ceramics may became dominant. At the MPB composition $(6$ mol\% BZT), the crystal structure of ceramics is considered to be a coexistence of rhombohedral and tetragonal phase. ${ }^{14)}$ As the free energy of rhombohedral phase is close to that of tetragonal phase, when applied a electric field, these two phase are easy to change each other. It is helpful to promote the
Table 1. Properties of BNT-BZT6, BNT-BZT8 and BNBT6 LeadFree Piezoelectric Ceramics

\begin{tabular}{cccr}
\hline Ceramic composition & $d_{33}(\mathrm{pC} / \mathrm{N})$ & $k_{\mathrm{p}}(\%)$ & $\varepsilon_{33}{ }^{\mathrm{T}} / \varepsilon_{0}$ \\
\hline BNT-BZT6 & 168 & 27 & 950 \\
BNT-BZT8 & 163 & 21 & 892 \\
BNBT6 & 125 & 20.8 & 580 \\
\hline
\end{tabular}

movement and polarization of ferroelectric active ion at this case, leading to the increase in dielectric constant $\varepsilon_{33}{ }^{T} / \varepsilon_{0}$ and electromechanical coupling factor $k_{\mathrm{p}}$. The increase in piezoelectric constant $d_{33}$ at MPB composition may be attributed to an increase flexibility in domain wall. ${ }^{8)}$ At higher amount of $\mathrm{BZT}(>6 \mathrm{~mol} \% \mathrm{BZT})$, chemical modification plays a major role on the properties of BNT-BZT ceramics again.

The dielectric, piezoelectric properties of BNT-BZT6, BNT-BZT8 and a typical lead-free piezoelectric ceramics such as BNT-BT6 are shown in Table 1. Among them, BNT-BZT6 has the highest $d_{33}$ and $k_{\mathrm{p}}$. It is obvious that BNT-BZT6 is promising candidate for lead-free piezoelectric ceramic and can be used in practical applications.

From the X-ray diffraction patterns and the dependence of the piezoelectric and dielectric properties on the chemical composition, the BNT-BZT system was found to have MPB, similar to PZT, which enhance the piezoelectric properties. From these results, it is certain that piezoelectric performance can be improved by selecting compounds with a different crystal structure and forming a microstructure using their mixtures.

\section{Conclustions}

BNT-BZT100x ternary system focusing on the MPB between tetragonal and rhombohedral phase has been investigated. These materials can be synthesized by conventional ceramic sintering technique. The crystalline structure, dielectric and piezoelectric properties of these ceramics were studied. Results of X-ray diffraction (XRD) show that the ceramics exhibit pure perovskite structure. The measurements of dielectric and piezoelectric properties reveal that the BNTBZT6 ceramic provide relatively high piezoelectric constant $d_{33}$ (up to $168 \mathrm{pC} / \mathrm{N}$ ) and high electromechanical coupling factor $k_{\mathrm{p}}$ (up to $27 \%$ ). It is obvious that this piezoelectric ceramic is promising candidate for lead-free piezoelectric ceramic and can be used in practical applications.

Acknowledgements The project was funded by the Key Laboratory of Specially Functional Materials and Advanced Manufacturing Technology, South China University of Technology, Ministry of Education, China, Natural Science Foundation of South China University of Technology, China and Research Program of student, South China University of Technology, China.

\section{References}

1) Smolenskii, G. A., Isupov, V. A., Agranovskaya, A. I. and Krainik, N. N., Sov. Phys. Solid State, Vol. 2, pp. 2651-2654 (1961).

2) Zrirgzds, J. V., Kapostis, P. P. and Kruzina, T. V., Ferroelectrics, Vol. 40, pp. 75-77 (1980).

3) Suchanicz, J., Roleder, K., Kania, A. and Handerek, J., Ferroelectrics, Vol. 77, pp. 107-110 (1988).

4) Hagiyev, M. S., Ismaizade, I. H. and Abiyev, A. K., Ferroelectrics, Vol. 56, pp. 215-217 (1984).

5) Takenaka, T., Maruyama, K. and Sakata, K., Jpn. J. Appl. Phys., Vol. 30, pp. 2236-2239 (1991). 
6) Takenaka, T., Okuda, T. and Takegahara, K., Ferroelectrics, Vol. 196, pp. 175-178 (1997).

7) Nagata, H., Koizumi, N. and Takenaka, T., Key Eng. Mater., Vol. 37-40, pp. 169-170 (1999).

8) Sasaki, A., Chiba, T., Mamiya, Y. and Otsuki, E., Jpn. J. Appl. Phys., Vol. 38, pp. 5564-5567 (1999).

9) Herabut, A. and Safari, A., J. Am. Ceram. Soc., Vol. 80, pp. 2954-2958 (1997).

10) Hennigs, D. and Schnell, A., J. Am. Ceram. Soc., Vol. 65, pp. 539-544 (1982).
11) Paul, W. R., Seung-Eek, P. and Susan, T. M., Pennsylvania 16802: Materials Research Raboratory, The Pennsylvania State University (1998).

12) Jaffe, B., Roth, R. S. and Margullo, S., J. Res. Bur. Stnd., Vol. 55, pp. 239-243 (1955).

13) Onoe, M. and Jumonji, H., J. Acoust. Soc. Am., Vol. 41, pp. 974-980 (1967).

14) Isupov, V. A. and Stolypin, Y. E., J. Phys. Soc. Japan, Vol. 28, pp. 312-316 (1970). 